\title{
Extratos de morus nigra I. (amora-preta) e bixa orellana I. (urucum) para substituição dos corantes hematoxilina e eosina (HE) na técnica histológica de rotina
}

\author{
Extracts of morus nigra I. (black mulberry) and bixa orellana I. (urucum) in the substitution \\ of hematoxylin and eosin stain (HE) in the routine histological technique
}

Extractos de morus nigra I. (mora negra) y bixa orellana I. (urucum) para sustitución de los colorantes hematoxilina y eosina (HE) en la técnica histológica de rutina

Monique Amanda Batista Oliveira ${ }^{1}$, Samira Thaís Pereira ${ }^{1}$, Adriana Rodrigues dos Anjos Mendonça $^{1}$, Eliakim José de Souza Lopes ${ }^{1}$, Fiorita Gonzales Lopes Mundim¹, Rodrigo Machado Pereira $^{1 *}$

\section{RESUMO}

Objetivo: Avaliar a aplicabilidade da coloração pelos extratos de amora-preta (Morus nigra L.) e urucum (Bixa orellana L.) para substituição da hematoxilina e eosina, respectivamente, na técnica histológica rotineira. Métodos: Frutos de amora-preta e sementes de urucum foram utilizadas para a preparação de corantes histológicos, de acordo com os métodos já descritos na literatura. A efetividade dos produtos foi testada em secções histológicas de encéfalo, coração e pele de ratos. Os cortes foram submetidos à bateria de coloração com a solução de amora-preta ou hematoxilina, seguido da coloração com urucum ou eosina. As lâminas foram avaliadas ao microscópio quanto à efetividade de coloração em uma escala de 0 a 3. Os valores foram analisados estatisticamente. Resultados: Foi possível observar um padrão distinto de coloração de estruturas celulares e teciduais pelos produtos naturais alternativos. O citoplasma apresentou coloração alaranjada pelo extrato de urucum, enquanto que os componentes nucleares eram destacados com pigmentação azul pelos corantes de amora. Pela avaliação da intensidade de coloração, a combinação hematoxilina e urucum obteve maior similaridade ao padrão de hematoxilina e eosina. Conclusão: De maneira inédita, foi comprovado que ambos os corantes naturais alternativos podem ser utilizados em conjunto para realizar uma dupla coloração em substituição à técnica de hematoxilina e eosina, sendo considerados como alternativas interessantes para a histotecnologia.

Palavras chave: Produtos Naturais, Pigmentos Orgânicos, Histologia, Lâminas, Tecidos.

\section{ABSTRACT}

Objective: The objective of this study was to evaluate the applicability of the staining by extracts of black mulberry (Morus nigra L.) and urucum (Bixa orellana L.) in order to respectively substitute hematoxylin and eosin staining procedure in the routine histological technique. Methods: Black mulberry fruits and urucum seeds were used in preparation of histological stains according to literature reported methods. The effectiveness of staining was tested on histological sections of encephalon, heart and skin of rats. The sections were submitted to the staining battery with extracts of blackberry or hematoxylin, followed by urucum or eosin staining. The slides were observed through microscope in order to evaluate staining effectiveness. A 0 to 3 scale was determined. The values were statistically analyzed. Results: It was observed a distinct pattern of staining of cell and tissue structures. The cytoplasm presented yellowish coloration by the urucum extract, while the nuclear components were featured with blue pigmentation by the blackberry stain. Color intensity evaluation demonstrates that hematoxylin and urucum combination is similar to hematoxylin and eosin staining. Conclusion: In an unprecedented way, it has been proven that both natural alternative dyes can be used together to perform a double stainig in substitution of the hematoxylin and eosin technique, being considered as interesting alternative for histotechnology.

Keywords: Natural Products, Organic Pigments, Histology, Slides, Tissues.

\footnotetext{
${ }^{1}$ Universidade do Vale do Sapucaí (UNIVÁS), Pouso Alegre-MG, Brasil.

*E-mail: rodrigomachadopereira@yahoo.com.br
} 


\section{RESUMEN}

Objetivo: El objetivo fue evaluar la aplicabilidad de la coloración por los extractos de mora negra (Morus nigra L.) y urucum (Bixa orellana L.) colorantes hematoxilina y eosina en la técnica histológica rutinaria. Métodos: Los frutos de amora negra y las semillas de urucum se utilizaron para la preparación de colorantes histológicos, de acuerdo con los métodos ya descritos en la literatura. La efectividad de los productos fue probada en secciones histológicas de encéfalo, corazón y piel de ratones Wistars, sometidos a la batería de coloración con los extractos de mora o hematoxilina, seguido de la coloración con urucum o eosina. Las láminas fueron evaluadas al microscopio en cuanto a la efectividad de coloración en una escala de 0 a 3 . Los valores fueron analizados estadísticamente. Resultados: Fue posible observar un patrón distinto de coloración, donde el citoplasma presentó coloración amarillento por el extracto de urucum y los componentes nucleares eran destacados con pigmentación azul por los colorantes de mora. Por la evaluación de intensidad de coloración, fue posible observar que la combinación hematoxilina y urucum obtuvo resultados similares al hematoxilina y eosina. Conclusión: De manera inédita, se ha comprobado que los dos colorantes alternativos pueden ser utilizados en conjunto para realizar una doble coloración en sustitución a la técnica rutinaria, siendo considerados como alternativas interesantes para la histotecnología.

Palabras clave: Productos naturales, Pigmentos Orgánicos, Histología, Láminas, Tejidos.

\section{INTRODUÇAO}

O exame anatomopatológico é essencial para o diagnóstico laboratorial de diversas doenças, que além da avaliação macroscópica, inclui a análise histopatológica por microscopia óptica. Neste caso, diversos tipos de corantes são necessários na visualização das células e componentes teciduais, já que os mesmos apresentam boa parte de suas estruturas sem cores ou transparentes. Na prática rotineira da preparação histológica, os corantes hematoxilina e eosina (HE) são comumente utilizados, pois promovem uma boa diferenciação e contraste das estruturas, uma vez que se comportam como corantes básicos e ácidos, respectivamente (JUNQUEIRA e CARNEIRO, 2013).

A hematoxilina é um corante extraído do cerne da árvore Haematoxylum campechianum, conhecida também como Pau Campeche. É classificado como corante básico, do qual possui afinidade a estruturas ácidas das células, como ácidos nucleicos, glicosaminoglicanos e glicoproteínas ácidas (JUNQUEIRA e CARNEIRO, 2013). A obtenção natural desse corante exige muito tempo, pois necessita da oxidação da hematoxilina transformando-a em hemateína. Para acelerar a produção, agentes oxidantes podem ser adicionados transformando esse corante natural em um composto perigoso (ALLISON, 1999; AVWIORO, 2011). Deste modo, foram propostos alguns tipos de corantes naturais alternativos para a substituição da hematoxilina como, por exemplo, o suco de amoras da espécie Rubus fructicosus (AL-TIKRITTI e WALKER, 1978). Além desta, frutos da espécie Morus nigra (amora-preta) já haviam sido utilizadas para a preparação de corantes biológicos (TOUSSON e AL-BEHBEHANI, 2011).

Por outro lado, a eosina é um corante sintético que possui característica ácida. Portanto, é comumente empregada na coloração de estruturas básicas como, por exemplo, mitocôndrias, grânulos de secreção, proteínas citoplasmáticas e colágeno (JUNQUEIRA e CARNEIRO, 2013). Informações toxicológicas revelam que eosina amarelada pode causar grave irritação na pele e nos olhos, e após ingestão pode provocar vários efeitos adversos sobre órgãos como fígado e rins. A inalação reduz a capacidade de troca gasosa dos pulmões, e seus metabólitos também são altamente tóxicos e cancerígenos (MITTAL et al., 2013). Da mesma maneira, diversos corantes naturais alternativos foram propostos em substituição deste corante como, por exemplo, extratos de urucum (Bixa orellana) (ROHDE et al., 2006), crajirú (Arrabidaea chica) (DE SOUZA et al., 2007) e hena (Lawsonia inermis) (ALAWA et al., 2015).

A utilização de corantes histológicos naturais alternativos na técnica de coloração de rotina proporcionaria maior segurança, baixo custo na produção e agilidade de obtenção dos corantes devido à abundância de determinadas plantas presentes no território brasileiro. Nesse sentido, podemos observar que corantes obtidos de amoras, por apresentar propriedade de coloração de estruturas ácidas, poderia ser utilizado em conjunto com o corante alternativo extraído de sementes de urucum, pois este segundo apresenta propriedade de coloração de estruturas básicas. Deste modo, o uso de ambos promoveria uma dupla coloração, proporcionando um contraste entre as estruturas. 
Analisando essas condições, neste estudo foi avaliado a aplicabilidade do uso conjunto do corante natural obtido de M. nigra L. (Amora-preta) e o corante extraído de B. orellana L. (Urucum) em substituição dos corantes hematoxilina e eosina na coloração histológica de rotina.

\section{MATERIAL E MÉTODOS}

\section{Coleta do material vegetal}

Os frutos de urucum (B. orellana L.) foram coletados em uma propriedade rural $\left(21^{\circ} 54^{\prime} 10.1^{\prime \prime} \mathrm{S}\right.$, $45^{\circ} 51^{\prime} 04.5^{\prime \prime W}$ ) localizado entre os municípios de Turvolândia e São João da Mata (Minas Gerais, Brasil), no período do mês de maio de 2016. Já os frutos de amora-preta ( $M$. nigra L.) foram coletados em uma propriedade rural $\left(22^{\circ} 23^{\prime} 18,3^{\prime \prime} \mathrm{S}, 45^{\circ} 53^{\prime} 15,6^{\prime \prime} \mathrm{W}\right)$ no distrito de Cachoeira de Minas (Minas Gerais, Brasil) no mês de setembro de 2016. Ambos materiais foram levados ao Laboratório Multidisciplinar do Curso de Ciências Biológicas, separadas as sementes dos frutos de urucum e armazenados a $-20^{\circ} \mathrm{C}$.

\section{Obtenção dos órgãos animais e preparação do material histológico}

Para realização deste estudo, foram utilizados órgãos de ratos Wistar previamente incluídos em parafina. O material foi derivado de um projeto de pesquisa anterior, aprovado pelo Comitê de Ética em Pesquisa da Universidade do Vale do Sapucaí sob protocolo 160/12. Foram realizadas secções histológicas de encéfalo, pele e coração em micrótomo rotativo (Lupetec MRP 2015) com espessura de 4 um (micrômetros) e distendidos em banho-maria, a aproximadamente $60^{\circ} \mathrm{C}$. Os cortes foram pescados e secos em estufa a $65^{\circ} \mathrm{C}$.

\section{Preparação dos corantes}

O corante de urucum foi obtido por um método adaptado de Rohde et al. (2006), onde $20 \mathrm{~g}$ de sementes de urucum foram adicionadas em $100 \mathrm{ml}$ de álcool etílico 92,8\%, submetidos a agitação a 200 RPM durante 24 horas seguido de filtração.

O suco de amora-preta foi obtido, por um método adaptado de Al-Tikritti e Walker (1978), através da maceração dos frutos, seguido de centrifugação e filtração para obtenção de um extrato límpido.

A constituição dos corantes oriundos do extrato de amora consiste em:

- Fórmula $\mathrm{A}: 100 \mathrm{ml}$ de suco de amora incorporado à $1,0 \mathrm{~g}$ de cloreto de alumínio e $1,2 \mathrm{ml}$ solução de cloreto férrico à $10 \%$;

- Fórmula B: $100 \mathrm{ml}$ de suco da amora incorporado a 5,0g de cloreto de sódio, $1,2 \mathrm{ml}$ de solução de cloreto férrico à $10 \%$ e 3,0ml ácido acético glacial;

- Suco da amora puro.

Por fim, os extratos foram armazenados em frascos escuros para melhor conservação do corante.

\section{Bateria de coloração}

As secções histológicas foram desparafinizadas em estufa a $65^{\circ} \mathrm{C}$ por 1 hora, seguido de 3 banhos de xilol. A hidratação foi realizada em série alcoólica decrescente, água corrente e água destilada. Em seguida, foi realizada a coloração por hematoxilina ou pelos corantes de amora-preta. O excesso foi removido em água corrente e destilada. Foi efetuado uma prévia desidratação em etanol $70 \%$ para realização da contra coloração por eosina ou extrato de urucum. Após esta última etapa, os cortes histológicos foram imersos em três banhos de etanol absoluto para a remoção do excesso de corante e finalizadas com 3 banhos de xilol para a clarificação. As lâminas foram montadas em verniz com lamínulas e levadas ao microscópio para avaliação (Tabela 1). 
Tabela 1: Combinações de colorações realizadas.

\begin{tabular}{|c|c|c|c|c|c|c|c|c|}
\hline & HxE & $\mathrm{HxU}$ & AAxE & AAxU & ABXE & $A B x U$ & APxE & APxU \\
\hline Amora - Fórmula A & & & $X$ & $x$ & & & & \\
\hline Amora - Fórmula B & & & & & $\mathbf{X}$ & $\mathbf{X}$ & & \\
\hline Amora - Pura & & & & & & & $\mathbf{x}$ & $\mathbf{x}$ \\
\hline Urucum & & $\mathbf{x}$ & & $\mathbf{x}$ & & $\mathbf{x}$ & & $\mathbf{x}$ \\
\hline Hematoxilina & $\mathbf{X}$ & $x$ & & & & & & \\
\hline Eosina & $\mathbf{x}$ & & $\mathbf{x}$ & & $x$ & & $\mathbf{X}$ & \\
\hline
\end{tabular}

Fonte: Dados da pesquisa, 2018.

Legenda: $\mathrm{HxE}$ : hematoxilina e eosina; $\mathrm{HxU}$ : hematoxilina e urucum; $\mathrm{AAxE}$ : amora fórmula $\mathrm{A}$ e eosina; $\mathrm{AAxU}$ : amora fórmula $A$ e urucum; $A B \times E$ : amora fórmula b e eosina; $A B x U$ : amora fórmula $B$ e urucum; $A P x E$ : amora pura e eosina; APXU: amora pura e urucum.

\section{Análise de coloração}

Após a confecção de todas as lâminas, as mesmas foram levadas ao microscópio óptico onde foi realizada a análise das colorações. As identificações das lâminas foram ocultadas de modo que não influenciasse a avaliação. Foram atribuídos valores para qualidade da coloração. Para tanto, foram classificados como 0 (zero), quando não houve a coloração de nenhuma estrutura; 1 (um), quando houve coloração discreta; 2 (dois), quando houve coloração efetiva de núcleo ou citoplasma e 3 (três), quando houve melhor qualidade de coloração.

\section{Análise estatística}

Foram confeccionadas 3 lâminas de cada material histológico (encéfalo, pele e coração) para cada uma das 8 colorações. Deste modo, a partir da análise microscópica, foram obtidas 9 amostras de cada combinação de corantes. Os dados foram submetidos ao teste estatístico Anova one-way e ao pós-teste de Tukey pelo software GraphPad Prism versão 5.01. Foi considerado significativo a diferença nas comparações que obtiveram o valor de $p<0,05$.

\section{RESULTADOS}

A partir das combinações realizadas, foi possível observar padrões distintos de coloração. Os corantes de amora nas combinações $A A x E, A A x U, A B x E, A B x U$ promoveram a coloração dos núcleos celulares, que apresentam estruturas ácidas, como o DNA e RNA. Deste modo, heterocromatina e nucléolos tornaram-se evidentes. Por outro lado, o urucum promoveu a coloração de componentes básicos. Como exemplo, podemos observar a coloração de fibras colágenas em secções de pele. Além disso, constatou-se a coloração de fibras musculares e fibras nervosas em cortes de coração e encéfalo (Figura 1, 2 e 3). 
Figura 1. Colorações em cortes de encéfalo pelas combinações de corantes de amora, urucum, hematoxilina e eosina. A região de substância cinzenta evidencia núcleos celulares.

\section{Eosina}
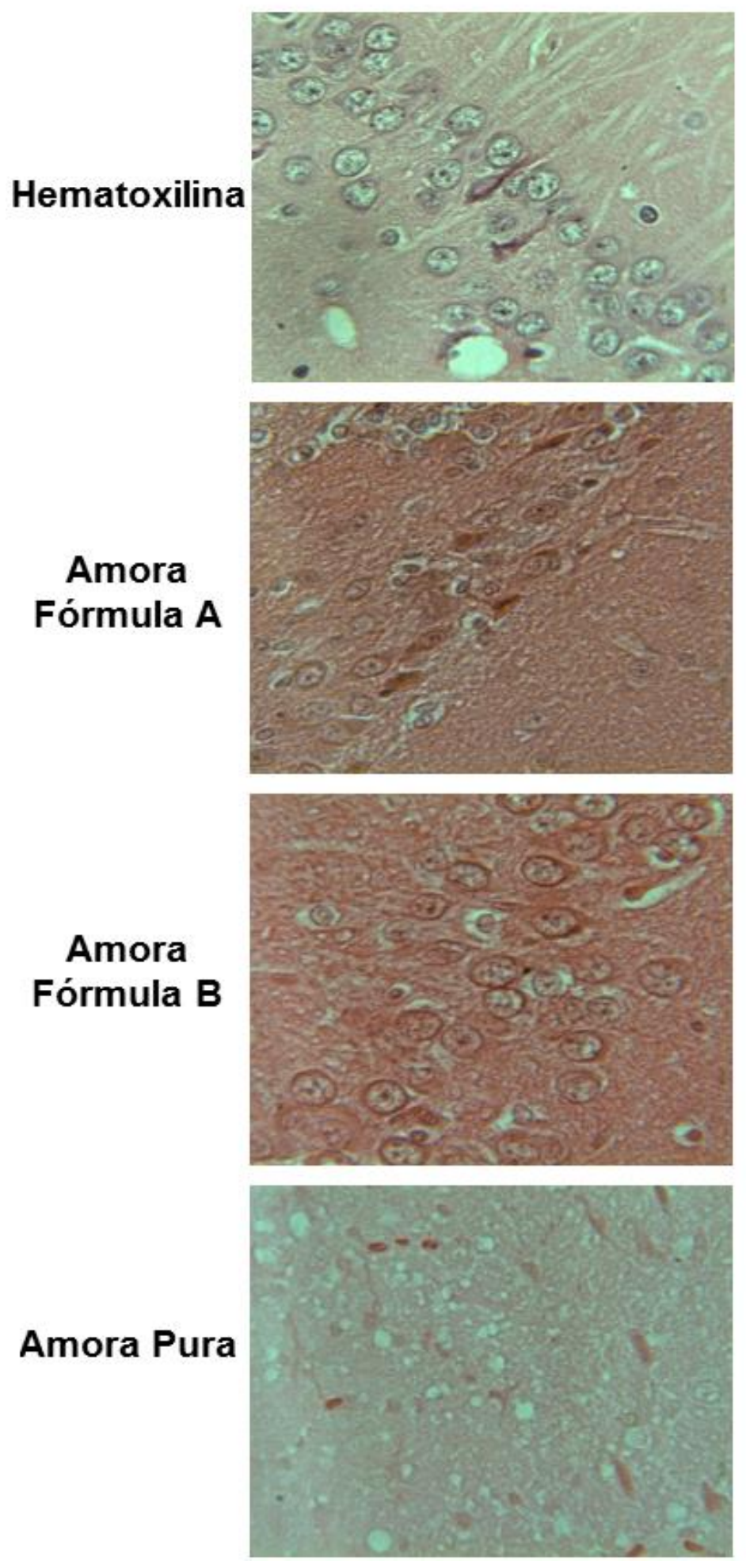

\section{Urucum}
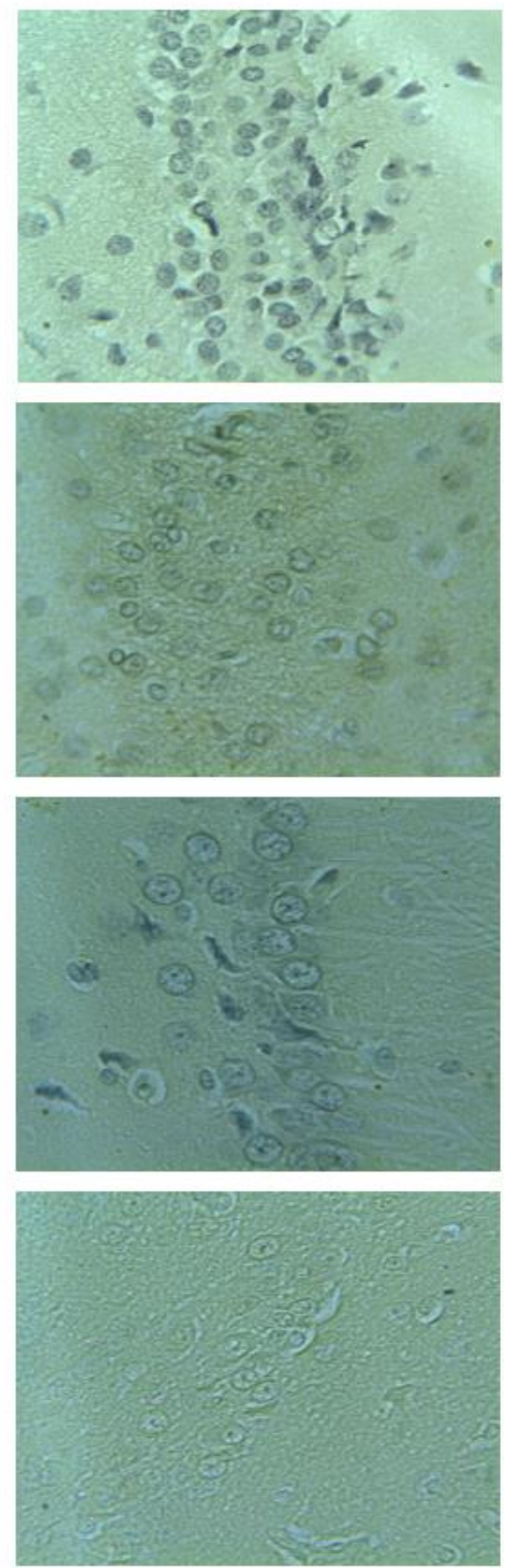

Fonte: Dados da pesquisa, 2018. 
Figura 2. Colorações realizadas em secções de pele pelas combinações de corantes de amora, urucum, hematoxilina e eosina. As camadas da epiderme e do início da derme foram evidenciadas.

\section{Eosina}

Hematoxilina
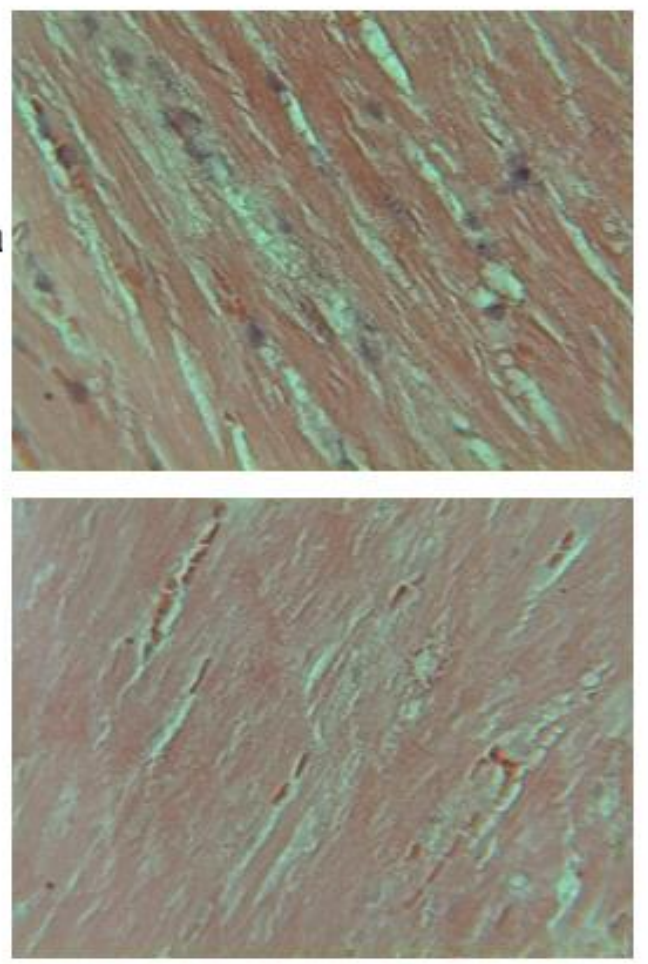

Amora

Fórmula A

Amora

Fórmula B
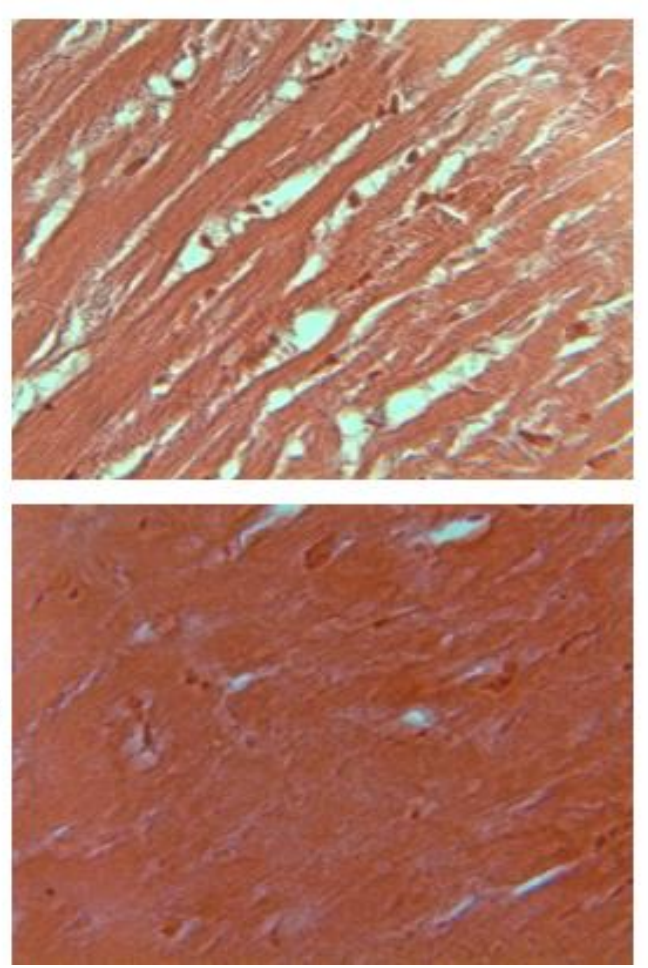

Urucum
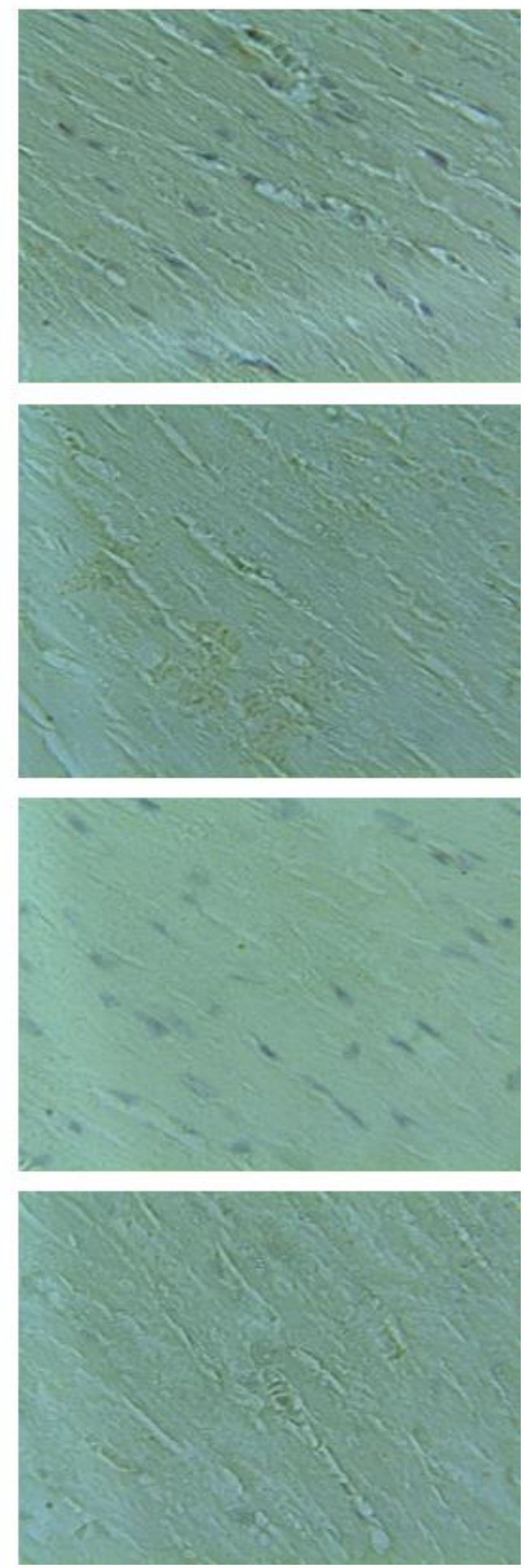

Fonte: Dados da pesquisa, 2018. 
Figura 3. Seç̧ões de coração coradas pelas combinações dos corantes testados, evidenciando a camada do miocárdio, que contém o tecido muscular estriado cardíaco constituído por células alongadas que apresentam discos intercalares.

\section{Eosina}

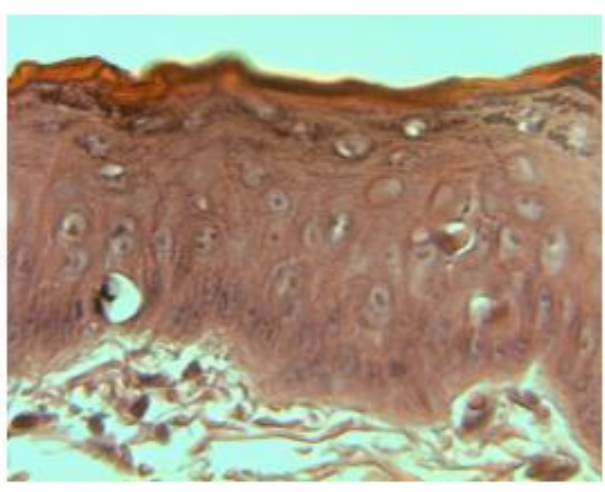

Hematoxilina

Amora

Fórmula A

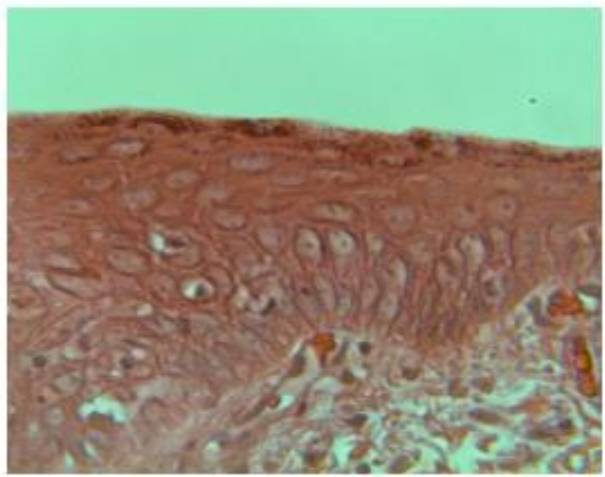

Amora

Fórmula B
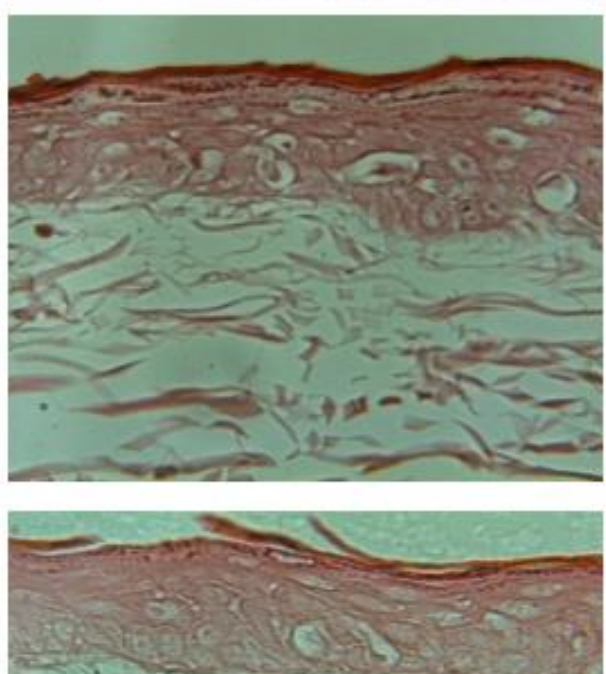

Amora Pura

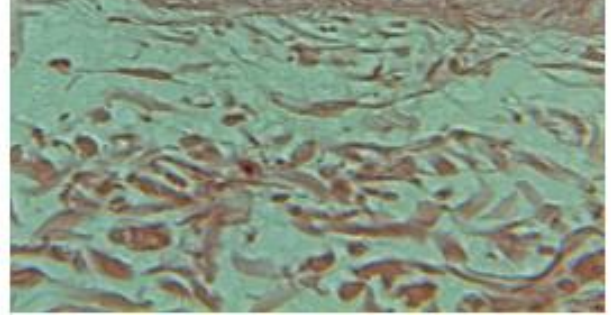

Urucum
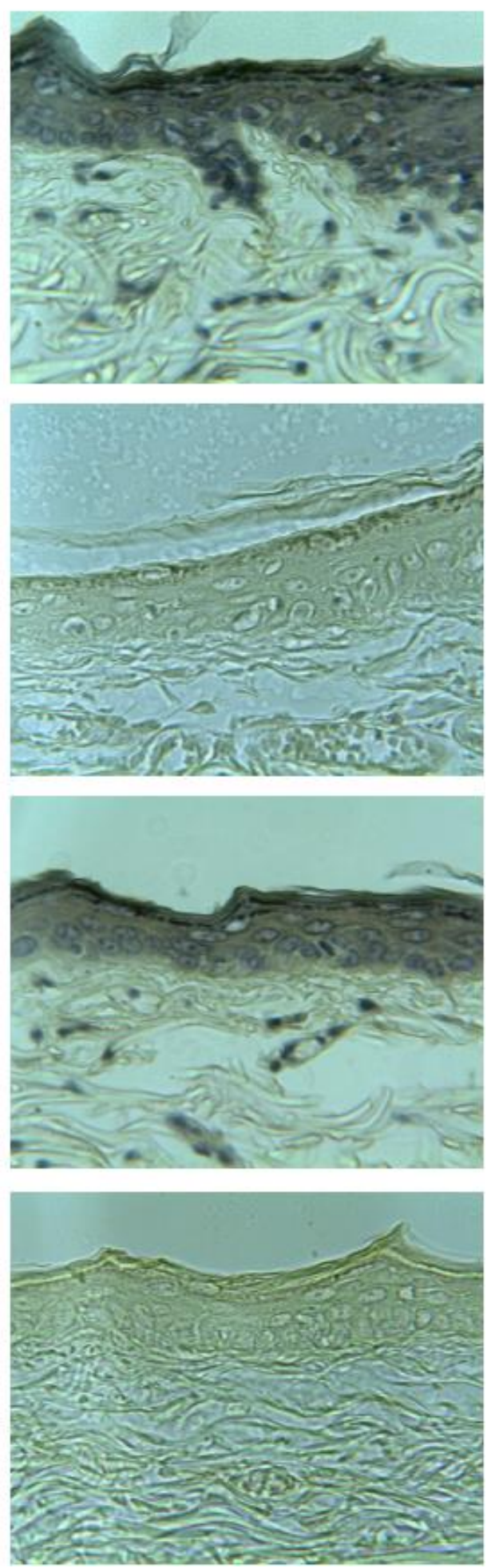

Fonte: Dados da pesquisa, 2018. 
Dentre as combinações de corantes, foi observado que algumas apresentaram melhores resultados em relação à coloração de hematoxilina e eosina. A coloração de hematoxilina e urucum obteve resultados de intensidade e qualidade similares ao padrão. Embora as demais combinações não tenham atingido a mesma intensidade, podemos observar que algumas combinações obtiveram uma boa coloração de núcleo ou citoplasma ou de ambos. Nota se que a combinação do extrato puro de amora e urucum não promoveu coloração considerável, de acordo com sua avaliação igual a 1 (Figura 4).

Figura 4. Análise da coloração das diferentes combinações em um intervalo de 0 a 3 . Os valores foram comparados ao resultado do método tradicional (HE).

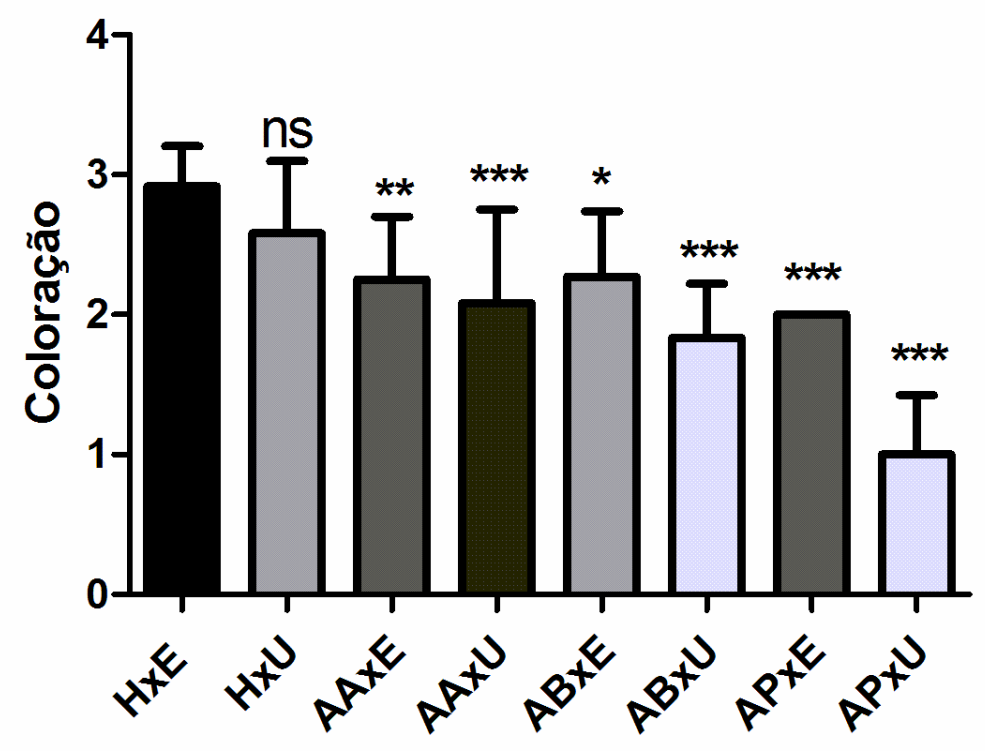

Fonte: Dados da pesquisa, 2018.

Legenda: ${ }^{*} p<0,05 ;{ }^{* *} p<0,01 ;{ }^{* * *} p<0,001$ e ns: não significativo.

Os resultados obtidos neste trabalho comprovaram que a associação desses dois corantes naturais alternativos promoveu um padrão de coloração distinto de estruturas celulares e teciduais, uma vez que o citoplasma apresentou coloração alaranjada pelo extrato de urucum, enquanto que os componentes nucleares eram destacados com pigmentação azul pelos corantes de amora.

\section{DISCUSSÃO}

A técnica de coloração hematoxilina-eosina é rotineiramente utilizada para fins de diagnóstico laboratorial anatomopatológico. Porém, algumas restrições vão de encontro ao uso frequente destas soluções corantes. Dentre elas, destaca-se a dificuldade de manufatura e uso de metais pesados na composição da hematoxilina, que, assim como a eosina, emerge uma característica de toxicidade humana e ambiental (ALLISON, 1999; AVWIORO, 2011; MITTAL et al., 2013). Alguns corantes extraídos de vegetais foram propostos como alternativas por apresentarem maior segurança de manipulação, baixo custo e agilidade de obtenção (ALAWA et al., 2015; BASSEY, 2012; DE SOUZA et al., 2007). Desta forma, este trabalho apresentou como objetivo avaliar a aplicabilidade do uso conjunto do corante natural obtido de Morus nigra L. (Amora-preta) e o corante extraído de Bixa orellana L. (Urucum) em substituição dos corantes hematoxilina e eosina na coloração histológica de rotina. 
Experimentos descritos na literatura já demonstraram que o extrato do urucum (B. orellana L.) possui potencial para coloração histológica, uma vez que apresenta afinidade a estruturas acidófilas (ROHDE et al., 2006). Esta planta é encontrada nas florestas tropicais, especialmente no Brasil, e utilizada pelos índios brasileiros como maquiagem tribal, proteção contra o sol e insetos. O urucum é também considerado um dos corantes naturais mais utilizados na indústria alimentícia sendo encontrado em manteiga, queijo, produtos de panificação, óleos, sorvetes entre outros. Tais características se dão devido à abundante presença de pigmentos isômeros denominados bixina e norbixina. (DE MORAIS, 2005; TOCCHINI e MERCADANTE, 2001).

A bixina corresponde a cerca de $80 \%$ dos pigmentos do urucum, sendo obtida inclusive em boa quantidade pela extração etanólica (SILVA et al., 2010). Sua capacidade de ligação a proteínas tem sido atribuída a interações hidrofóbicas (ZHANG e ZHONG, 2012). Neste sentido, é plausível afirmar que a coloração de fibras proteicas da matriz extracelular e proteínas citoplasmáticas nos ensaios realizados nesta pesquisa possam ter ocorrido devido a esta propriedade, uma vez que as condições experimentais eram favoráveis.

Os resultados deste estudo também demonstraram que os componentes nucleares foram destacados pelos corantes de amora da espécie Morus nigra L., assim como extratos derivados da espécie Rubus fructicosus promovem o mesmo padrão de coloração acidófila. Esta característica foi particularmente atribuída às suas antocianinas (AL-TIKRITTI e WALKER, 1978).

Ensaios com antocianinas já foram amplamente realizados na tentativa de eleger um novo substituto à hematoxilina (DAPSON et al., 2010). Embora estes pigmentos estejam presentes em várias espécies de amora, os frutos de $M$. nigra apresentam concentração majoritária (HASSIMOTO et al., 2007). Considerando também a disponibilidade doméstica, resistência á descoloração e boa propriedade de coloração das estruturas basófilas, é possível declarar que o corante de amora-preta é um bom substituinte à hematoxilina em procedimentos histológicos de rotina.

Nota-se discrepância nas colorações realizadas pelos corantes de amora-preta, onde o suco puro não promoveu resultados satisfatórios. Comparando os corantes de amora (Fórmula $A A, A B$ e AP), esta incapacidade ocorre aparentemente devido à ausência dos sais de ferro e alumínio. Estas substâncias atuam como mordentes, ou seja, ligantes entre o corante e as estruturas, utilizados para reforçar e melhorar a impregnação (YUSUF et al., 2017). Sua utilização é muito antiga, pois sabe-se que as populações da Mesopotâmia já usavam os metais em tinturas têxteis (LEVEY, 1955).

Assim como muitos substitutos da hematoxilina, as antocianinas também possuem a capacidade de quelar íons metálicos que atuam como mordentes (LILLIE et al., 1976). Deste modo, a presença de íons de alumínio (Fórmula $A A$ ) ou ferro (Fórmula $A B$ ) mostram-se indispensáveis, visto que é de extrema importância elementos que promovam a interação entre as moléculas de antocianinas e as estruturas básicas do tecido.

\section{CONCLUSÃO}

De maneira inédita, foi comprovado que ambos os corantes naturais alternativos podem ser utilizados em conjunto para realizar uma dupla coloração em substituição à técnica de hematoxilina e eosina. Embora tenha-se observado que a intensidade e tonalidade de coloração dos produtos naturais apresentados é ligeiramente diferente à técnica rotineira, o mesmo padrão de coloração de componentes estruturais foi identificado, sem prejuízos ao observador. Desta forma, essa associação vem como uma alternativa frente à substituição dos corantes importados por obtidos da flora brasileira, de fácil utilização, que oferecem maior segurança ao meio ambiente. 


\section{REFERÊNCIAS}

1. ALAWA JN, GIDEON GO, ADETIBA B et al. Comparative tissue stainability of Lawsonia inermis (Henna) and eosin as counterstains to hematoxylin in brain tissues. Microscopy and Microanalysis, 2015; 21(2): 343-350.

2. ALLISON RT. Haematoxylin--from the wood. Journal of clinical pathology, 1999; 52(7): 527-528.

3. AL-TIKRITTI SA, WALKER F. Anthocyanin BB: a nuclear stain substitute for haematoxylin. Journal of clinical pathology, 1978; 31(2): 194-196.

4. AVWIORO OG. Histochemical uses of haematoxylin-a review. Journal of Physics: Conference Series, 2011 ; $1: 24-34$.

5. BASSEY RB et al. Factors influencing extract of Hibiscus sabdariffa staining of rat testes. Biotechnic \& Histochemistry, 2012: 87(6): 403-407.

6. DE SOUZA HQ, HIDALGO AF, CHAVES FCM. Preparo do corante de crajirú (Arrabidaea chica (Bonpl.) B. Verl.) e sua aplicação em Histologia. In: Embrapa Amazônia Ocidental-Artigo em anais de congresso (ALICE). In: Congresso Brasileiro De Olericultura, 47.; Simpósio Brasileiro Sobre Cucurbitáceas, 4., 2007, Porto Seguro, BA. Resgatando e valorizando as hortaliças subutilizadas. Horticultura Brasileira, 2007; 25(1): s36. Suplemento.

7. DAPSON, R.; HOROBIN, R. W.; KIERNAN, J. Hematoxylin shortages: their causes and duration, and other dyes that can replace hemalum in routine hematoxylin and eosin staining. Biotechnic \& Histochemistry, v. 85, n. 1, p. 55-63, 2010.

8. DE MORAIS SM, DANTAS JDAP, DA SILVA ARA et al. Plantas medicinais usadas pelos índios Tapebas do Ceará. Brazilian Journal of Pharmacognosy, 2005; 15(2): 169-177.

9. HASSIMOTTO NMA, GENOVESE MI, LAJOLO FM. Identification and characterization of anthocyanins from wild mulberry (Morus nigra L.) growing in Brazil. Food science and technology international, 2007; 13(1): 17-25.

10. JUNQUEIRA LCU, CARNEIRO J. Histologia Básica. 13 ed. Rio de Janeiro: Guanabara Koogan, $2017 ; 568 p$.

11. LEVEY M. Dyes and dyeing in ancient Mesopotamia. Journal of Chemical Education, 1955; 32(12): 625-629.

12. LILLIE RD, PIZZOLATO P, DONALDSON PT. Hematoxylin substitutes: a survey of mordant dyes tested and consideration of the relation of their structure to performance as nuclear stains. Stain technology, 1976; 51(1): 25-41.

13. MITTAL A et al. Adsorption of hazardous dye Eosin Yellow from aqueous solution onto waste material De-oiled Soya: Isotherm, kinetics and bulk removal. Journal of Molecular Liquids, 2013; 179: 133-144.

14. ROHDE DC et al. O uso do corante urucum (Bixa orellana L.) na técnica de coloração histológica. Revista Brasileira de Análises Clínicas, 2006; 38(2): 119-121.

15. SILVA PI, NACHTIGALL AM, STRINGHETA PC. Eficiência de solventes na obtenção e caracterização de corantes de urucum (Bixa orellana L.). Boletim do Centro de Pesquisa de Processamento de Alimentos, 2010; 28: 115-124.

16. TOCCHINI L, MERCADANTE AZ. Extração e determinação, por CLAE, de bixina e norbixina em coloríficos. Ciência e tecnologia de Alimentos, 2001; 21(3): 310-313.

17. TOUSSON E, AL-BEHBEHANI B. Black mulberries (Morus nigra) as a natural dye for animal tissues staining. Animal Biology, 2011; 61(1): 49-56.

18. YUSUF M, SHABBIR M, MOHAMMAD F. Natural colorants: Historical, processing and sustainable prospects. Natural products and bioprospecting, 2017; 7(1): 123-145.

19. ZHANG Y, ZHONG Q. Binding between bixin and whey protein at $\mathrm{pH} 7.4$ studied by spectroscopy and isothermal titration calorimetry. Journal of agricultural and food chemistry, 2012; 60(7): 1880-1886. 